\title{
Analysis of genetic diversity and trait correlations among Korean landrace rice (Oryza sativa L.)
}

\author{
F.P. Li ${ }^{1 *}$, Y.S. Lee ${ }^{2 *}$, S.W. Kwon ${ }^{3}$, G. Li ${ }^{1}$ and Y.J. Park ${ }^{1,4}$ \\ ${ }^{1}$ Department of Plant Resources, College of Industrial Sciences, \\ Kongju National University, Yesan, Republic of Korea \\ ${ }^{2}$ Department of Medical Biotechnology, College of Medical Sciences, \\ Soonchunhyang University, Asan, South Korea \\ ${ }^{3}$ Department of Plant Bioscience, \\ College of Natural Resources and Life Science, Pusan National University, \\ Milyang, Republic of Korea \\ ${ }^{4}$ Legume Bio-Resource Center of Green Manure, \\ Kongju National University, Yesan, Republic of Korea \\ *These authors contributed equally to this study. \\ Corresponding author: Y.J. Park \\ E-mail: yjpark@kongju.ac.kr
}

Genet. Mol. Res. 13 (3): 6316-6331 (2014)

Received April 8, 2013

Accepted August 22, 2013

Published April 14, 2014

DOI http://dx.doi.org/10.4238/2014.April.14.12

\begin{abstract}
This study analyzed 394 Korean rice landrace accessions, including 93 waxy varieties, for polymorphisms using 29 simple sequence repeat (SSR) markers. In total, 381 alleles served as raw data for estimating the genetic diversity (GD) and population structure. The number of alleles per locus ranged from 3 to 44 (average $=13.14$ ). The expected heterozygosity and polymorphism information content (PIC) ranged from 0.0341 to 0.9358 (mean $=0.5623$ ) and from 0.0783 to 0.9367 (mean $=0.5839$ ), respectively. The mean GDs in waxy, low amylose content, intermediate amylose content, and high amylose content (HAC) varieties were $0.6014,0.5922,0.5858$, and 0.7232 , respectively,
\end{abstract}


whereas the mean PIC values for each SSR locus were 0.5701, 0.5594, 0.5550 , and 0.6926 , respectively. HAC varieties had the highest GD and PIC. Consistent with clustering by genetic distances, a model-based structural analysis revealed 3 subpopulations. Analysis of molecular variance revealed that the between-population component of genetic variance was $22.35 \%$, and that of the within-population component was $77.65 \%$. Significant correlations were observed between eating quality and protein content $(\mathrm{r}=-0.262), \mathrm{K}^{+}(\mathrm{r}=-0.655), \mathrm{Mg}^{2+}(\mathrm{r}=-0.680)$, $1000-\mathrm{GW}(\mathrm{r}=0.159)$, and amylose content $(\mathrm{r}=-0.134)$. The overall $F_{\mathrm{ST}}$ value was 0.2235 , indicating moderate differentiation among the groups. Analysis of variance of the 3 genetic groups (mean of 9 phenotypic and 5 physicochemical traits) by the Duncan multiple range test showed significant differences in 10 traits. This preliminary study represents a first step toward more efficient conservation and greater utilization of rice landraces to broaden the genetic bases of commercially grown varieties.

Key words: Oryza sativa; Simple sequence repeat; Landrace; Genetic diversity; Population structure

\section{INTRODUCTION}

Rice (Oryza sativa L.) is one of the most important cereal crops in the world, especially in Asian countries such as China, Korea, and Japan. Among these countries, Korea has a long history of rice cultivation and is important in the East Asiatic gene center, in part because of rice seeds that were excavated from a Bronze Age ( $\sim 3000$ years ago) site (Hammer, 2005). Currently, rice is a staple food for more than $40 \%$ of the world's population. Thus, improving rice quality has become one of the foremost considerations for rice buyers and breeding programs. Eating and cooking qualities are particularly important because most rice is consumed cooked. Rice-eating quality is strongly related to a number of easily measurable physicochemical characteristics, including the amount of starch, which is determined through indirect indices, namely, the amylose content (AC), gel consistency, and gelatinization temperature. These parameters reflect the starch functionality of the rice grain, and $\mathrm{AC}$ is widely recognized as an important determinant for various rice products (Juliano, 1998). Landraces maintained by farmers are endowed with tremendous genetic variability because they have been subjected to subtle selection over long periods of time. This aids in the adaptation of landraces to wide agro-ecological niches, and they have unmatched qualitative traits and medicinal properties. Although rice landraces are not heavily utilized in modern breeding programs, they are considered valuable genetic resources. Therefore, uncovering the unused alleles and qualitative traits of landraces is important to understand their genetic structure and to maximize the conservation and utilization of exotic genetic resources.

Molecular markers are important tools for determining the genetic diversity (GD) in many species and for managing plant genetic resources. In contrast to morphological traits, molecular markers can reveal differences among genotypes based on DNA polymorphisms, providing a direct, reliable, and efficient tool for germplasm characterization, conservation, and management. Many DNA markers have been developed and have become powerful tools for detecting the GD within and between populations, including restriction fragment length 
polymorphisms (Sun et al., 2001), amplified fragment length polymorphisms (Bao et al., 2006), random amplified polymorphic DNA (Rabbani et al., 1998), sequence-characterized amplified regions (Li and Park, 2012), simple sequence repeats (SSRs) (Giarrocco et al., 2007), and single nucleotide polymorphisms (McNally et al., 2009). SSRs are the markers of choice for crop improvement in many species because they are reliable and easy to score (Gupta and Varshney, 2000; Moe and Park, 2012). SSR markers are co-dominant, multi-allelic, and require only a small amount of DNA for scoring. To date, more than 2500 SSR primer pairs have been developed in rice (McCouch et al., 2002), offering a tremendous opportunity to gain insight into the genetic structure of the rice genome. In Korea, the GenBank of the Rural Development Administration (RDA) maintains about 1100 rice landrace accessions, and these exotic accessions have not been or are rarely included in breeding programs; thus, genetic characterization is needed to ensure the long-term success of breeding programs and to maximize the conservation and utilization of the rice germplasm in Korea. Studies of the GD of the Korean rice germplasm have been conducted using various molecular markers (Jeong et al., 1999; Song et al., 2002; Lee et al., 2006). These studies have not only provided useful information for understanding the genetic basis of various rice gene pools established in different geographic regions but also facilitated the selection of new gene sources for breeding programs.

In this study, 394 rice landraces collected from South Korea were evaluated for their GD and population structure based on the AC using SSR markers. We also examined the degree of genetic differentiation of morphologically and genetically defined groups. Our findings will promote local rice conservation programs and increase the utilization of the rice germplasm in Korea.

\section{MATERIAL AND METHODS}

\section{Plant materials and DNA extraction}

The 394 rice landrace accessions, which included waxy (No. 1-93), low AC (LAC) (No. 94-285), intermediate AC (IAC) (No. 286-367), and high AC (HAC) (No. 368-394) varieties, were obtained from the National Agrobiodiversity Center of the RDA (Table 1). Each accession was grown in a greenhouse, and DNA was extracted from the fresh leaves of 15-dayold seedlings using a DNA extraction kit (Qiagen, Valencia, CA, USA). The relative purity and concentration of the extracted DNA were estimated with a NanoDrop ND-1000 spectrophotometer (Qiagen). The final concentration of each DNA sample was adjusted to $20 \mathrm{ng} / \mu \mathrm{L}$.

\section{Amylose content analysis}

AC was measured using the method of Perez and Juliano (1978). Briefly, $100 \mathrm{mg}$ rice flour was placed into a 100-mL volumetric flask, $1 \mathrm{~mL} 95 \%$ ethanol and $9 \mathrm{~mL} 1 \mathrm{M}$ aqueous sodium hydroxide were added, and the contents were boiled for $8 \mathrm{~min}$. After cooling to room temperature, the volume was made up with distilled water, and $5 \mathrm{~mL}$ solution was put into a

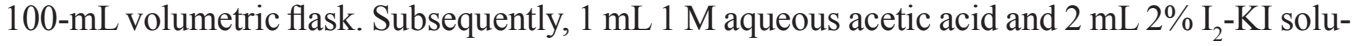
tion were added, and the volume was raised to $100 \mathrm{~mL}$ with distilled water. The absorbance of the solution was measured at $620 \mathrm{~nm}$ with a spectrophotometer. A standard curve that was made simultaneously using rice samples of known $\mathrm{AC}$ was used to calculate the $\mathrm{AC}$ of each sample. 
Genetic diversity and correlations among landrace rice

Table 1. Three hundred and ninety-four rice landrace accessions used in this study and their model-based population genetic groups based on 29 SSR markers.

\begin{tabular}{|c|c|c|c|c|c|c|c|c|}
\hline Code & No. IT & $\begin{array}{l}\text { Distance-based } \\
\text { groups }^{\text {b }}\end{array}$ & Code & No. IT & $\begin{array}{l}\text { Distance-based } \\
\text { groups }^{\mathrm{b}}\end{array}$ & Code & No. IT ${ }^{\mathrm{a}}$ & $\begin{array}{l}\text { Distance-based } \\
\text { groups }^{\mathrm{b}}\end{array}$ \\
\hline 1 & 004753 & Admixtured & 133 & 005970 & Admixtured & 265 & 009243 & POP1 \\
\hline 2 & 004770 & POP3 & 134 & 005980 & Admixtured & 266 & 009244 & POP1 \\
\hline 3 & 004771 & POP3 & 135 & 005993 & POP1 & 267 & 009245 & POP1 \\
\hline 4 & 005046 & POP1 & 136 & 005994 & Admixtured & 268 & 009250 & POP1 \\
\hline 5 & 005051 & POP1 & 137 & 006000 & POP3 & 269 & 009251 & Admixtured \\
\hline 6 & 005126 & POP1 & 138 & 008438 & POP1 & 270 & 009264 & POP3 \\
\hline 7 & 004688 & POP1 & 139 & 006084 & POP1 & 271 & 009265 & POP1 \\
\hline 8 & 005736 & POP1 & 140 & 006087 & POP1 & 272 & 009267 & POP1 \\
\hline 9 & 005743 & POP1 & 141 & 006103 & POP1 & 273 & 007442 & POP3 \\
\hline 10 & 005756 & POP3 & 142 & 006114 & POP1 & 274 & 009797 & POP1 \\
\hline 11 & 008732 & Admixtured & 143 & 006116 & POP1 & 275 & 010161 & POP1 \\
\hline 12 & 151696 & POP3 & 144 & 006119 & Admixtured & 276 & 010339 & POP2 \\
\hline 13 & 005835 & POP1 & 145 & 006242 & Admixtured & 277 & 010340 & POP2 \\
\hline 14 & 006100 & Admixtured & 146 & 006243 & POP1 & 278 & 010345 & POP2 \\
\hline 15 & K026146 & POP3 & 147 & 006247 & POP1 & 279 & 010374 & POP2 \\
\hline 16 & 006620 & POP1 & 148 & 006258 & Admixtured & 280 & 010375 & Admixtured \\
\hline 17 & K026154 & POP1 & 149 & 006310 & POP3 & 281 & 006560 & POP1 \\
\hline 18 & K026181 & POP1 & 150 & 006328 & POP1 & 282 & 010417 & POP2 \\
\hline 19 & 006078 & POP1 & 151 & 006354 & POP3 & 283 & 006735 & POP1 \\
\hline 20 & K026160 & POP1 & 152 & 006366 & POP3 & 284 & 010555 & POP2 \\
\hline 21 & 006684 & POP3 & 153 & 006376 & Admixtured & 285 & 010577 & POP2 \\
\hline 22 & 007460 & Admixtured & 154 & 006386 & POP3 & 286 & 010582 & POP2 \\
\hline 23 & 007532 & POP1 & 155 & 007688 & Admixtured & 287 & 010704 & POP2 \\
\hline 24 & 007570 & POP1 & 156 & 006397 & POP1 & 288 & 009078 & POP1 \\
\hline 25 & 007714 & POP1 & 157 & 006400 & POP1 & 289 & 010721 & POP2 \\
\hline 26 & 007747 & Admixtured & 158 & 006404 & POP3 & 290 & 010726 & POP2 \\
\hline 27 & 008196 & POP3 & 159 & 006410 & POP3 & 291 & 010727 & POP2 \\
\hline 28 & K026190 & POP1 & 160 & 006483 & POP3 & 292 & 010728 & POP2 \\
\hline 29 & 008278 & POP1 & 161 & 006538 & POP2 & 293 & 007486 & Admixtured \\
\hline 30 & K026163 & Admixtured & 162 & 010627 & POP2 & 294 & 006380 & Admixtured \\
\hline 31 & 008388 & POP1 & 163 & 007999 & POP1 & 295 & K026192 & POP1 \\
\hline 32 & 008453 & POP1 & 164 & 006577 & POP3 & 296 & 006622 & POP2 \\
\hline 33 & 008725 & Admixtured & 165 & 009177 & POP1 & 297 & 155895 & POP3 \\
\hline 34 & K026155 & POP1 & 166 & 006663 & POP3 & 298 & 155896 & POP3 \\
\hline 35 & K026166 & POP1 & 167 & 006699 & POP1 & 299 & 007629 & POP1 \\
\hline 36 & 005915 & POP1 & 168 & 006768 & POP3 & 300 & 005754 & POP1 \\
\hline 37 & 008199 & POP3 & 169 & 006776 & POP3 & 301 & 173446 & Admixtured \\
\hline 38 & 008798 & POP1 & 170 & 009077 & POP3 & 302 & 008992 & POP3 \\
\hline 39 & 008883 & POP1 & 171 & 006818 & POP1 & 303 & 009117 & Admixtured \\
\hline 40 & 008999 & POP3 & 172 & 007268 & Admixtured & 304 & 006396 & POP1 \\
\hline 41 & K026171 & POP3 & 173 & 007286 & POP3 & 305 & 006554 & POP1 \\
\hline 42 & 009187 & POP1 & 174 & 007290 & POP1 & 306 & 006687 & POP1 \\
\hline 43 & 009192 & POP3 & 175 & 007389 & POP3 & 307 & K026148 & POP3 \\
\hline 44 & 010151 & POP2 & 176 & 007436 & POP3 & 308 & K026183 & POP1 \\
\hline 45 & 010275 & POP2 & 177 & 007458 & POP1 & 309 & K026150 & POP3 \\
\hline 46 & 010480 & POP2 & 178 & 005206 & POP3 & 310 & 006372 & POP1 \\
\hline 47 & 010565 & POP2 & 179 & 008891 & POP1 & 311 & 005989 & POP1 \\
\hline 48 & 010628 & POP2 & 180 & 007596 & POP1 & 312 & 006424 & POP3 \\
\hline 49 & 010631 & POP2 & 181 & 007598 & POP3 & 313 & 007274 & POP1 \\
\hline 50 & 010630 & Admixtured & 182 & 007604 & POP1 & 314 & K026161 & POP1 \\
\hline 51 & 110944 & POP2 & 183 & 007605 & POP1 & 315 & K026162 & POP1 \\
\hline 52 & 155897 & POP1 & 184 & 007660 & POP3 & 316 & K026156 & POP3 \\
\hline 53 & 008749 & POP1 & 185 & 007693 & POP3 & 317 & K026165 & Admixtured \\
\hline 54 & 009229 & POP1 & 186 & 007740 & POP3 & 318 & K026179 & Admixtured \\
\hline 55 & K026149 & POP1 & 187 & 007742 & POP3 & 319 & 006298 & POP3 \\
\hline 56 & K026180 & POP1 & 188 & 007792 & POP3 & 320 & 007254 & POP1 \\
\hline 57 & K026147 & POP3 & 189 & 007801 & POP1 & 321 & 007446 & Admixtured \\
\hline 58 & K026164 & POP1 & 190 & 010625 & POP3 & 322 & 007578 & POP3 \\
\hline 59 & 006302 & Admixtured & 191 & 007981 & POP1 & 323 & 005693 & POP3 \\
\hline 60 & 008710 & Admixtured & 192 & 008344 & Admixtured & 324 & 005689 & POP1 \\
\hline 61 & K026168 & POP3 & 193 & 008255 & POP1 & 325 & 005070 & POP3 \\
\hline
\end{tabular}


F.P. Li et al.

\begin{tabular}{|c|c|c|c|c|c|c|c|c|}
\hline Code & No. IT & $\begin{array}{l}\text { Distance-based } \\
\text { groups }^{\mathrm{b}}\end{array}$ & Code & No. IT ${ }^{\mathrm{a}}$ & $\begin{array}{l}\text { Distance-based } \\
\text { groups }^{\text {b }}\end{array}$ & Code & No. IT & $\begin{array}{l}\text { Distance-based } \\
\text { groups }^{\text {b }}\end{array}$ \\
\hline 62 & K026186 & POP1 & 194 & 008268 & POP1 & 326 & 005681 & POP3 \\
\hline 63 & K026188 & Admixtured & 195 & 008267 & Admixtured & 327 & 005683 & POP1 \\
\hline 64 & K026157 & Admixtured & 196 & 008277 & POP1 & 328 & 006064 & POP1 \\
\hline 65 & K026158 & POP3 & 197 & 008286 & POP1 & 329 & 006112 & POP1 \\
\hline 66 & K026167 & POP1 & 198 & 008289 & POP1 & 330 & 006559 & POP3 \\
\hline 67 & K026169 & Admixtured & 199 & 008295 & POP3 & 331 & 007592 & POP1 \\
\hline 68 & K026172 & POP1 & 200 & 008293 & POP1 & 332 & 008590 & POP3 \\
\hline 69 & K026173 & POP1 & 201 & 008296 & POP3 & 333 & 006005 & POP3 \\
\hline 70 & K026175 & Admixtured & 202 & 008310 & POP3 & 334 & 007746 & POP3 \\
\hline 71 & 005052 & Admixtured & 203 & 008314 & POP1 & 335 & 006266 & POP3 \\
\hline 72 & K026182 & Admixtured & 204 & 008355 & POP1 & 336 & 005682 & Admixtured \\
\hline 73 & K026184 & POP1 & 205 & 008357 & POP3 & 337 & 006129 & POP3 \\
\hline 74 & K026185 & Admixtured & 206 & 008382 & POP3 & 338 & 007278 & POP1 \\
\hline 75 & K026195 & POP1 & 207 & 008385 & POP3 & 339 & 005718 & POP1 \\
\hline 76 & K026152 & POP2 & 208 & 008390 & POP1 & 340 & 004775 & POP1 \\
\hline 77 & 009590 & POP3 & 209 & 005095 & POP3 & 341 & 008361 & Admixtured \\
\hline 78 & 005205 & POP3 & 210 & 008401 & POP3 & 342 & K026145 & POP3 \\
\hline 79 & 007900 & POP1 & 211 & 008408 & POP3 & 343 & 008982 & POP3 \\
\hline 80 & K026189 & POP1 & 212 & 008469 & POP3 & 344 & 005044 & POP1 \\
\hline 81 & K026187 & POP1 & 213 & 008471 & POP1 & 345 & 006657 & POP1 \\
\hline 82 & 007903 & POP1 & 214 & 008528 & POP3 & 346 & 009172 & POP1 \\
\hline 83 & 007585 & POP1 & 215 & 007633 & POP3 & 347 & 009173 & POP3 \\
\hline 84 & 007270 & Admixtured & 216 & 008530 & Admixtured & 348 & 007687 & POP1 \\
\hline 85 & K026159 & Admixtured & 217 & 008579 & POP1 & 349 & 006089 & POP1 \\
\hline 86 & 007464 & POP3 & 218 & 008580 & POP1 & 350 & 005679 & Admixtured \\
\hline 87 & 010707 & POP2 & 219 & 008951 & POP3 & 351 & 006066 & POP1 \\
\hline 88 & 004760 & POP1 & 220 & 008591 & POP3 & 352 & 006260 & POP1 \\
\hline 89 & K026144 & POP1 & 221 & 008599 & POP3 & 353 & 007487 & Admixtured \\
\hline 90 & K026191 & POP1 & 222 & 008672 & POP3 & 354 & 005742 & POP3 \\
\hline 91 & 007717 & POP1 & 223 & 008700 & POP3 & 355 & 007631 & POP1 \\
\hline 92 & 006125 & POP1 & 224 & 008717 & POP3 & 356 & 006010 & POP1 \\
\hline 93 & K026170 & POP1 & 225 & 008734 & POP1 & 357 & 006578 & POP1 \\
\hline 94 & 010276 & POP2 & 226 & 008743 & Admixtured & 358 & 007634 & POP3 \\
\hline 95 & 004692 & POP1 & 227 & 008804 & Admixtured & 359 & 006596 & POP1 \\
\hline 96 & 004694 & POP3 & 228 & 008816 & Admixtured & 360 & 203619 & POP1 \\
\hline 97 & 004697 & POP3 & 229 & 008820 & POP1 & 361 & 173445 & POP1 \\
\hline 98 & 004768 & POP1 & 230 & 008981 & Admixtured & 362 & 006520 & POP1 \\
\hline 99 & 004769 & Admixtured & 231 & 008831 & POP1 & 363 & 007975 & POP1 \\
\hline 100 & K026177 & POP1 & 232 & 008850 & POP1 & 364 & 006556 & POP2 \\
\hline 101 & 004811 & POP3 & 233 & 008897 & Admixtured & 365 & 008799 & POP3 \\
\hline 102 & 004839 & POP3 & 234 & 008895 & POP1 & 366 & 006138 & POP1 \\
\hline 103 & 010612 & POP2 & 235 & 005678 & POP1 & 367 & 008983 & POP3 \\
\hline 104 & 004861 & POP1 & 236 & 007721 & POP1 & 368 & 007684 & POP1 \\
\hline 105 & 004899 & POP1 & 237 & 008986 & POP2 & 369 & 005762 & POP1 \\
\hline 106 & 004914 & POP3 & 238 & 008996 & POP3 & 370 & 006385 & POP3 \\
\hline 107 & 005040 & POP1 & 239 & 009023 & POP3 & 371 & 005508 & POP3 \\
\hline 108 & 008413 & POP2 & 240 & 009056 & POP3 & 372 & 009142 & Admixtured \\
\hline 109 & 005057 & POP1 & 241 & 009059 & Admixtured & 373 & 005505 & POP3 \\
\hline 110 & 005068 & POP3 & 242 & 009060 & Admixtured & 374 & 005893 & POP3 \\
\hline 111 & 005076 & POP1 & 243 & 009065 & POP1 & 375 & 007630 & POP3 \\
\hline 112 & 005133 & POP1 & 244 & 009069 & Admixtured & 376 & 009057 & POP3 \\
\hline 113 & K026178 & POP1 & 245 & 009073 & POP3 & 377 & 005660 & Admixtured \\
\hline 114 & 005142 & POP1 & 246 & 009118 & POP2 & 378 & 005691 & POP1 \\
\hline 115 & 005216 & POP1 & 247 & K026174 & POP1 & 379 & 005509 & POP1 \\
\hline 116 & K026193 & Admixtured & 248 & 009123 & POP3 & 380 & 008741 & POP3 \\
\hline 117 & 005223 & POP1 & 249 & 009128 & POP2 & 381 & K026176 & Admixtured \\
\hline 118 & 005500 & POP1 & 250 & 006772 & POP1 & 382 & 007245 & Admixtured \\
\hline 119 & 005504 & POP1 & 251 & 006551 & POP1 & 383 & 007559 & POP2 \\
\hline 120 & 008806 & Admixtured & 252 & 009129 & POP1 & 384 & 006303 & POP2 \\
\hline 121 & 005506 & POP1 & 253 & 009138 & POP3 & 385 & 006522 & POP1 \\
\hline 122 & 007807 & POP1 & 254 & 009169 & POP1 & 386 & 008888 & POP3 \\
\hline
\end{tabular}

Continued on next page 


\begin{tabular}{|c|c|c|c|c|c|c|c|c|}
\hline Code & No. IT ${ }^{\mathrm{a}}$ & $\begin{array}{l}\text { Distance-based } \\
\text { groups }^{\mathrm{b}}\end{array}$ & Code & No. IT & $\begin{array}{l}\text { Distance-based } \\
\text { groups }^{\mathrm{b}}\end{array}$ & Code & No. IT & $\begin{array}{l}\text { Distance-based } \\
\text { groups }^{\text {b }}\end{array}$ \\
\hline 123 & 008189 & POP3 & 255 & 009174 & POP1 & 387 & 009120 & POP1 \\
\hline 124 & 005657 & POP1 & 256 & 006151 & Admixtured & 388 & 009189 & POP1 \\
\hline 125 & 010274 & POP1 & 257 & 005677 & POP3 & 389 & 010376 & POP2 \\
\hline 126 & 005694 & Admixtured & 258 & 005987 & POP1 & 390 & K026153 & POP2 \\
\hline 127 & 005716 & POP1 & 259 & 009180 & POP1 & 391 & 005882 & Admixtured \\
\hline 128 & 005908 & POP1 & 260 & 009182 & POP1 & 392 & K026194 & POP2 \\
\hline 129 & 005946 & POP3 & 261 & 009191 & POP3 & 393 & 007622 & POP1 \\
\hline 130 & K026151 & POP3 & 262 & 007282 & POP1 & 394 & 008984 & POP1 \\
\hline 131 & 173444 & POP3 & 263 & 009221 & POP2 & & & \\
\hline 132 & 005948 & POP1 & 264 & 009233 & Admixtured & & & \\
\hline
\end{tabular}

${ }^{a}$ No. IT. Introduction number of National Agrobiodiversity Center of RDA (Rural Development Administration) in Republic of Korea. ${ }^{b}$ As defined by the STRUCTURE program.

\section{Protein content (PC) analysis}

Crude protein was analyzed by the Association of Official Agricultural Chemists method (AOAC, 2005). Briefly, $1 \mathrm{~g}$ powdered white rice was mixed with concentrated sulfuric acid, digested for $45 \mathrm{~min}$ at $450^{\circ} \mathrm{C}$, and cooled to room temperature. Then, total nitrogen contents were measured using an automatic micro Kjeldahl system (FOSS: Kjeltec ${ }^{\circledR} 2300$ Analyzer Unit, Foss Tecator AB, Höganas, Sweden). PC was calculated from the measured total nitrogen content value using a conversion factor of 5.95.

\section{$\mathrm{K}^{+}$and $\mathrm{Mg}^{2+}$ analysis}

The mineral $\left(\mathrm{K}^{+}\right.$and $\left.\mathrm{Mg}^{2+}\right)$ contents were determined by using an inductively coupled plasma optical emission spectrometry (ICP-OES) (Thermo Fisher Scientific, Waltham, USA). Briefly, $0.3 \mathrm{~g}$ powdered white rice was combined with $\mathrm{HNO}_{3}$ and heated at $150^{\circ} \mathrm{C}$. After cooling and adding $\mathrm{HClO}_{4}$, the sample was reheated for complete oxidation. Again, after cooling to room temperature, samples were mixed with $\mathrm{HNO}_{3}$ and $\mathrm{dH}_{2} \mathrm{O}$ for digestion in a microwave (model Q 3000; Tektone, Franklin, NC, USA). Digested samples were filtered, and ICP-OES was conducted after adjusting the final volume to $100 \mathrm{~mL}$ with $\mathrm{dH}_{2} \mathrm{O}$.

\section{SSR analysis}

Markers were chosen according to their location on the rice genetic map and their suitability for high-throughput genotyping. In total, 29 SSR markers distributed across all 12 chromosomes were used (Table 2). All of the markers were obtained from GRAMENE (http:// www.gramene.org/). Amplification was performed in a $20-\mu \mathrm{L}$ volume containing $100 \mathrm{ng}$ template DNA, 1X PCR buffer, $0.2 \mathrm{mM}$ of each dNTP, $1 \mathrm{U}$ Taq DNA polymerase, 8 pmol of each reverse and fluorescently labeled M13 (-21) primer, and 2 pmol forward primer with an M13 $(-21)$ tail at its $5^{\prime}$-end. The conditions for amplification were as described in a previous study (Schuelke, 2000): $94^{\circ} \mathrm{C}$ for $3 \mathrm{~min} ; 30$ cycles of $94^{\circ} \mathrm{C}$ for $30 \mathrm{~s}, 55^{\circ} \mathrm{C}$ (the annealing temperature was changed depending on the primer) for $45 \mathrm{~s}$, and $72^{\circ} \mathrm{C}$ for $1 \mathrm{~min} ; 10$ cycles at $94^{\circ} \mathrm{C}$ for 30 $\mathrm{s}, 53^{\circ} \mathrm{C}$ for $45 \mathrm{~s}$, and $72^{\circ} \mathrm{C}$ for $1 \mathrm{~min}$; and a final extension at $72^{\circ} \mathrm{C}$ for $10 \mathrm{~min}$. The SSR alleles were resolved using a 3130xl Genetic Analyzer (Life Technologies Corp., Carlsbad, CA, 
USA) with the GeneScan 3.7 software and sized precisely against 6-carboxy-X-rhodamine molecular size standards using the Genotyper 3.7 software (Life Technologies Corp.).

Table 2. Total number of alleles, number of rare alleles, and GD index for 29 SSR loci in the 394 accessions.

\begin{tabular}{|c|c|c|c|c|c|c|c|c|}
\hline Marker & Map & Size range & $N_{\text {A }}$ & $N_{\mathrm{RA}}$ & MAF & $H_{\mathrm{E}}$ & GD & PIC \\
\hline RM021 & 11 & $129-197$ & 16 & 11 & 0.2944 & 0.7847 & 0.8088 & 0.7836 \\
\hline RM044 & 8 & $113-191$ & 15 & 9 & 0.4112 & 0.7431 & 0.7704 & 0.7476 \\
\hline RM048 & 2 & $121-235$ & 31 & 28 & 0.3706 & 0.7913 & 0.8213 & 0.8088 \\
\hline RM206 & 11 & $133-237$ & 44 & 38 & 0.1193 & 0.9358 & 0.9398 & 0.9367 \\
\hline RM214 & 7 & $111-223$ & 27 & 21 & 0.2716 & 0.8590 & 0.8499 & 0.8358 \\
\hline RM228 & 10 & $95-147$ & 12 & 8 & 0.4848 & 0.6400 & 0.7009 & 0.6683 \\
\hline RM231 & 3 & $110-192$ & 10 & 6 & 0.6954 & 0.4063 & 0.4954 & 0.4748 \\
\hline RM232 & 3 & $141-179$ & 20 & 13 & 0.2081 & 0.8632 & 0.8873 & 0.8775 \\
\hline RM235 & 12 & $89-137$ & 12 & 10 & 0.4975 & 0.2711 & 0.5790 & 0.4923 \\
\hline RM241 & 4 & $92-134$ & 16 & 10 & 0.3426 & 0.7695 & 0.8127 & 0.7929 \\
\hline RM246 & 1 & $94-116$ & 10 & 5 & 0.3376 & 0.7409 & 0.7544 & 0.7154 \\
\hline RM247 & 12 & $135-195$ & 15 & 11 & 0.3832 & 0.7397 & 0.7312 & 0.6917 \\
\hline RM249 & 5 & $121-207$ & 22 & 14 & 0.1447 & 0.8964 & 0.9116 & 0.9050 \\
\hline RM253 & 6 & $110-144$ & 12 & 7 & 0.4391 & 0.6710 & 0.7340 & 0.7024 \\
\hline RM257 & 9 & $136-170$ & 13 & 9 & 0.4492 & 0.6276 & 0.6972 & 0.6540 \\
\hline SBE & 2 & $140-218$ & 7 & 4 & 0.6168 & 0.5038 & 0.5516 & 0.4991 \\
\hline SSS & 6 & $193-215$ & 6 & 5 & 0.9594 & 0.0593 & 0.0791 & 0.0783 \\
\hline WxOligo & 6 & $100-124$ & 9 & 7 & 0.4721 & 0.5545 & 0.5787 & 0.4897 \\
\hline RM310 & 8 & $138-204$ & 18 & 13 & 0.2437 & 0.8212 & 0.8474 & 0.8305 \\
\hline RM3322 & 5 & $120-138$ & 7 & 5 & 0.8020 & 0.2792 & 0.3361 & 0.3094 \\
\hline RM3718 & 7 & $148-166$ & 8 & 6 & 0.5076 & 0.5312 & 0.5692 & 0.4793 \\
\hline RM3857 & 2 & $116-160$ & 15 & 9 & 0.2360 & 0.8320 & 0.8571 & 0.8414 \\
\hline RM6144 & 10 & $135-141$ & 3 & 1 & 0.8352 & 0.2425 & 0.2873 & 0.2599 \\
\hline RM6165 & 2 & $170-194$ & 3 & 2 & 0.9492 & 0.0341 & 0.0975 & 0.0948 \\
\hline RM6629 & 4 & $71-83$ & 5 & 3 & 0.8731 & 0.1521 & 0.2323 & 0.2239 \\
\hline RM12676 & 2 & $252-256$ & 3 & 1 & 0.4898 & 0.4987 & 0.5290 & 0.4177 \\
\hline RM16427 & 4 & 283-289 & 4 & 1 & 0.8629 & 0.1961 & 0.2487 & 0.2388 \\
\hline RM19159 & 5 & $159-201$ & 14 & 10 & 0.5076 & 0.5727 & 0.6855 & 0.6541 \\
\hline RM23455 & 8 & $310-314$ & 4 & 0 & 0.7132 & 0.2904 & 0.4603 & 0.4282 \\
\hline Total & & & 381 & 267 & & & & \\
\hline Mean & & & 13.14 & 9.21 & 0.5005 & 0.5623 & 0.6156 & 0.5839 \\
\hline
\end{tabular}

\section{Data analysis}

Basic statistics, including the total number of alleles, allele frequency, major allele frequency (MAF), and polymorphism information content (PIC), were calculated using Power Marker 3.25 (Liu and Muse, 2005). The variability at each locus was measured in terms of the number of alleles, expected heterozygosity $\left(H_{\mathrm{E}}\right)$, and genetic distance between each pair of accessions using the genetic analysis package POPGENE 1.31 (Yeh et al., 1999). The unweighted pair group method with an arithmetic mean (UPGMA) tree from shared allele frequencies was constructed using MEGA 4.0 (Tamura et al., 2007), which is embedded in Power Marker. The possible population was analyzed using the model-based program Structure 2.2 (Pritchard et al., 2000; Falush et al., 2003) without prior assignment of the accessions to populations. In this model, a number of populations $(K)$ are assumed to be present, each of which is characterized by a set of allele frequencies at each locus. Individuals in the sample are assigned to populations or jointly to more populations if their genotypes indicate that they are admixed. All loci are assumed to be independent, and each $K$ population is assumed to follow Hardy-Weinberg equilibrium. Posterior probabilities were estimated 
using the Markov chain Monte Carlo (MCMC) method. MCMC was run for 100,000 burn-in period lengths at fixed iterations of 5 for each fixed population number, followed by 200,000 iterations using a model allowing for admixture and correlated allele frequencies. At least 3 runs of Structure 2.2 were performed with $K$ ranging from 2 to 10, and an average likelihood value, $\operatorname{LnP}(\mathrm{D})$, across all runs was calculated for each value of $K$. The model choice criterion to detect the most probable value of $K$ was $\Delta K$, which is an ad hoc quantity related to the second-order change in the log probability of data with respect to the number of clusters inferred by Structure (Evanno et al., 2005). An individual was assigned to a group if $>70 \%$ of its genome fraction value derived from that group.

\section{Phenotypic trait associations and significance testing for population genetic groups}

The Duncan multiple range test (DMRT) was used to determine the significance among 3 groups by a model-based population structure analysis using Structure 2.2 (Pritchard et al., 2000) with 9 phenotypic traits and 5 physicochemical traits, including culm height $(\mathrm{cm}$, average of 20 plants), seed length ( $\mathrm{mm}$, average of 20 seeds), seed width ( $\mathrm{mm}$, average of 20 seeds), awn number per seed (average of 20 plants), number of panicles (average of 20 plants), panicle length ( $\mathrm{cm}$, average of 20 plants), seed coat color, days to flowering (number of days from the date of sowing to the date at which $50 \%$ of the plants begin flowering), and 1000-grain weight (g) (Satheeshkumar and Saravanan, 2012). The eating quality traits, as evaluated by the glossiness of cooked rice. In this study, 301 non-waxy varieties were measured using a Toyo-taste meter (Model: MA-90A and 90B) according to manufacturer operation protocols (Toyo Rice Polishing Machine Factory, Tokyo, Japan). To maintain the accuracy and consistency of measurements, rice flour of cv. Ilpoom was used as a reference every 30 samples. These phenotypic traits were tested for correlations using DMRT with the SPSS 16.0 software (SPSS Inc., Chicago, IL, USA).

\section{RESULTS}

\section{SSR polymorphisms and genetic variation in the landrace rice accessions}

The 29 SSR markers revealed 381 alleles among the 394 rice landrace accessions (Table 2). The number of observed alleles and rare alleles in the loci varied from 3 (RM6144, RM6165, and RM12676) to 44 (RM206) and from 0 (RM23455) to 38 (RM206), with averages of 13.14 and 9.21 alleles, respectively. The sizes of the alleles ranged from 71 to $314 \mathrm{bp}$ (Table 2). The database of allelic frequencies showed that the rare alleles (frequency $<0.05$ ) made up $70.1 \%$ of all alleles, whereas intermediate (frequency $=0.05-0.50$ ) and abundant alleles (frequency $>0.50$ ) represented 27 and $2.9 \%$ of all detected alleles, respectively. These results indicate the presence of a relatively large proportion of rare alleles, and most alleles were present at a low frequency among the rice landrace accessions that were studied (Figure 1). The GD varied from 0.0791 (SSS) to 0.9398 (RM206), with an average value of 0.6156 . The frequency of major alleles per locus and the $H_{\mathrm{E}}$ varied from 0.1193 (RM206) to 0.9594 (SSS) and from 0.0341 (RM6165) to 0.9358 (RM206), with averages of 0.5005 and 0.5623 , respectively. The PIC values ranged from a low value of 0.0783 (SSS) to a high value of 0.9367 (RM206), with an average of 0.5839 (Table 2). 


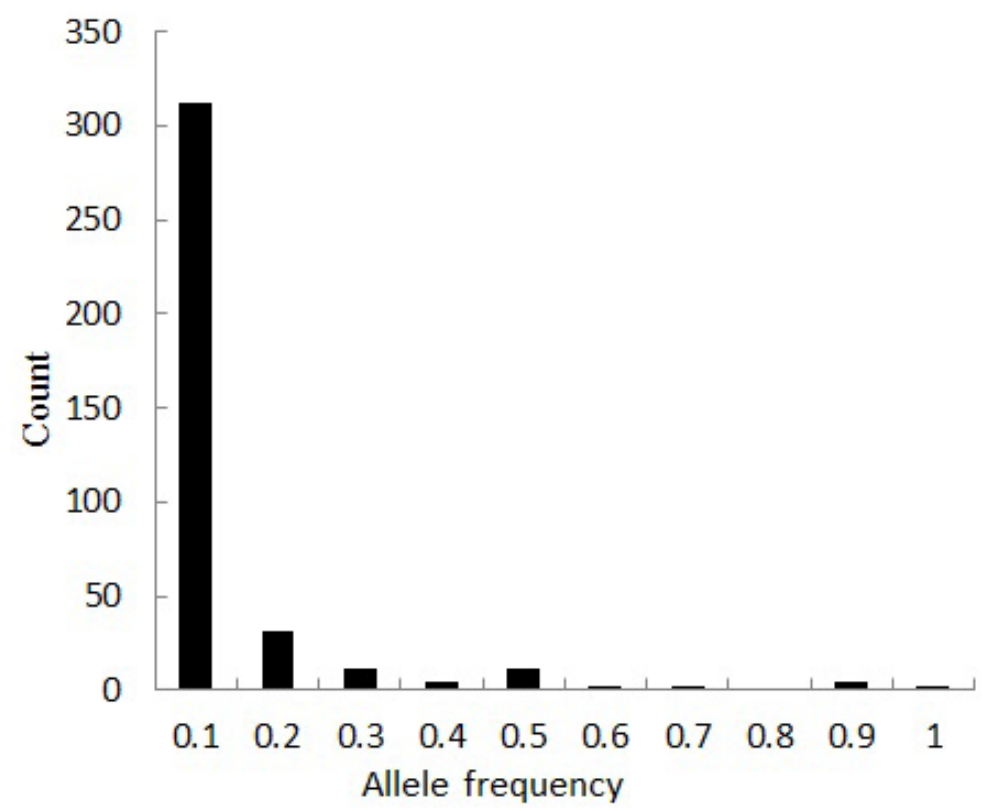

Figure 1. Histogram showing the allele frequencies for all 381 alleles in the 394 rice landrace accessions.

\section{Analysis of GD based on the AC}

$\mathrm{AC}$ is one of the most important predictors of eating quality in rice. The $\mathrm{AC}$ of milled rice can be classified as waxy (0-2\%), very low (3-9\%), low (10-19\%), intermediate $(20-24 \%)$, or high $(>24 \%)$ (Juliano, 1971). Waxy rice is used in foods such as desserts and snacks. Low-amylose varieties are soft and sticky and include nearly all temperate japonica rice varieties. Intermediate-amylose rice is soft but not sticky and is eaten by most consumers. High-amylose varieties are common among indica rice and are dry and fluffy when cooked, often becoming hard upon cooling. In this study, 93 waxy, 182 LAC, $82 \mathrm{IAC}$, and $37 \mathrm{HAC}$ rice varieties were analyzed for GD (Table 1). The GD among rice with the 4 different ACs is summarized in Table 3. The SSR markers revealed totals of 260 and 300 alleles in the waxy and LAC varieties with 8.97 and 10.34 alleles per locus, respectively, whereas the IAC and HAC varieties contained totals of 237 and 218 alleles with averages of 7.97 and 7.52 per locus, respectively. The mean GDs for each SSR locus in the waxy, LAC, IAC, and HAC rice varieties were $0.6014,0.5922,0.5858$, and 0.7232 , respectively, and the mean PIC values for each SSR locus were 0.5701, 0.5594, 0.5550, and 0.6926, respectively. Comparing GD, we found that the LAC varieties had the highest mean number of alleles. However, the values for GD and PIC were the highest in the HAC varieties, and the MAF per locus was the highest in the IAC varieties (0.5320). The MAF decreased in the order IAC $>$ LAC $>$ waxy $>$ HAC, but the order of average GD and PIC value was HAC > waxy > LAC > IAC (Table 3). The distribution of molecular genetic variation among and within the AC-based subgroups was estimated by analysis of molecular variance (AMOVA), which revealed that $4.61 \%$ of the total variation was among clusters and $95.39 \%$ of the variation was within clusters (Table 4 ). 
Table 3. Average number of alleles, GD, and PIC for different amylose contents (ACs).

\begin{tabular}{lccccccc}
\hline & $T_{\mathrm{A}}$ & $A_{\mathrm{A}}$ & $T_{\mathrm{RA}}$ & $A_{\text {RA }}$ & GD & PIC & MAF \\
\hline Overall & 381 & 13.14 & 334 & 11.52 & 0.6156 & 0.5839 & 0.5005 \\
Waxy & 260 & 8.97 & 143 & 4.93 & 0.6014 & 0.5701 & 0.5109 \\
LAC & 300 & 10.34 & 189 & 6.52 & 0.5922 & 0.5594 & 0.5235 \\
IAC & 237 & 7.97 & 126 & 4.34 & 0.5858 & 0.5550 & 0.5320 \\
HAC & 218 & 7.52 & 76 & 2.62 & 0.7232 & 0.6926 & 0.4023 \\
\hline
\end{tabular}

$T_{\mathrm{A}}=$ total alleles; $A_{\mathrm{A}}=$ average alleles; $T_{\mathrm{RA}}=$ total rare alleles; $A_{\mathrm{RA}}=$ average rare alleles; $\mathrm{GD}=$ gene diversity; $\mathrm{PIC}=$ polymorphic information content; $\mathrm{MAF}=$ major allele frequency; $\mathrm{LAC}=$ low $\mathrm{AC} ; \mathrm{IAC}=$ intermediate $\mathrm{AC}$; $\mathrm{HAC}=$ high $\mathrm{AC}$.

\begin{tabular}{l} 
Table 4. Results of AMOVA for the different populations. \\
\begin{tabular}{lrrrrr}
\hline Source of variation & d.f. & Sum of squares & Variance components & Percentage variation & P \\
\hline Amylose content & 3 & 68.10 & 0.11 & 4.61 & $<0.05$ \\
$\quad$ Among clusters & 392 & 1710.18 & 2.20 & 95.39 & \\
$\quad$ Within & & & 0.57 & 22.35 & $<0.05$ \\
Model-based population & 2 & 222.00 & 1.96 & 77.65 & \\
$\quad$ Among clusters & 328 & 1288.96 &
\end{tabular} \\
\hline
\end{tabular}

d.f. $=$ degrees of freedom.

\section{Population structure analysis}

The model-based grouping method was performed using all 394 rice landrace accessions and 29 SSR markers (Pritchard et al., 2000). Five runs of Structure 2.2 were conducted by setting the number of populations $(K)$ from 2 to 10 . For each run, the burnin time and replication number were both set to 100,000 . We used an ad hoc quantity $(\Delta K)$ to estimate likelihood values for a given $K$ if the distribution of $\mathrm{L}(K)$ did not show a clear mode for the true $K$ (Figure 2A). $\Delta K$ was developed to overcome the difficulty of interpreting the real $K$ values when influenced by factors such as inbreeding and departures from HardyWeinberg equilibrium, and it was tested under different simulation routines in which a real population structure was present (Falush et al., 2003). According to the second-order statistics developed for Structure (Evanno et al., 2005) to assess the number of subpopulations, the optimal value of $K=3$, which had the highest $\Delta K$, was identified (Figure 2B); at $K=3$, all 394 rice landrace accessions could be grouped into 3 populations, here designated as POP1, POP2, and POP3. The relatively small value of the alpha parameter $(\alpha=0.0739)$ revealed that most accessions originated from one primary ancestor, with a few admixed individuals. The degree of admixture, or alpha value, approached zero when calculated using Structure, which indicates that most individuals investigated here were essentially from separate populations. An alpha value $>1$ would have indicated that most populations were admixtures (Ostrowski et al., 2006). An individual having $>70 \%$ of its genome fraction value was assigned to a group. As shown in Figure 3, most of the accessions were clearly classified into 1 of the 3 subpopulations. POP1 consisted of 182 accessions, including waxy (48), LAC (87), IAC (38), and HAC (9) varieties; POP2 consisted of 38 accessions, mainly containing LAC (16), waxy (9), and IAC (8) varieties; and POP3 consisted of 111 accessions, which were predominantly LAC (61) and IAC (25) varieties. In total, 332 accessions (84\% of 394 accessions) were each clearly assigned to a single subpopulation, whereas 63 accessions (16\% of 394 accessions) in the sample were categorized as having admixed ancestry (Figure 3 and Table 1). 

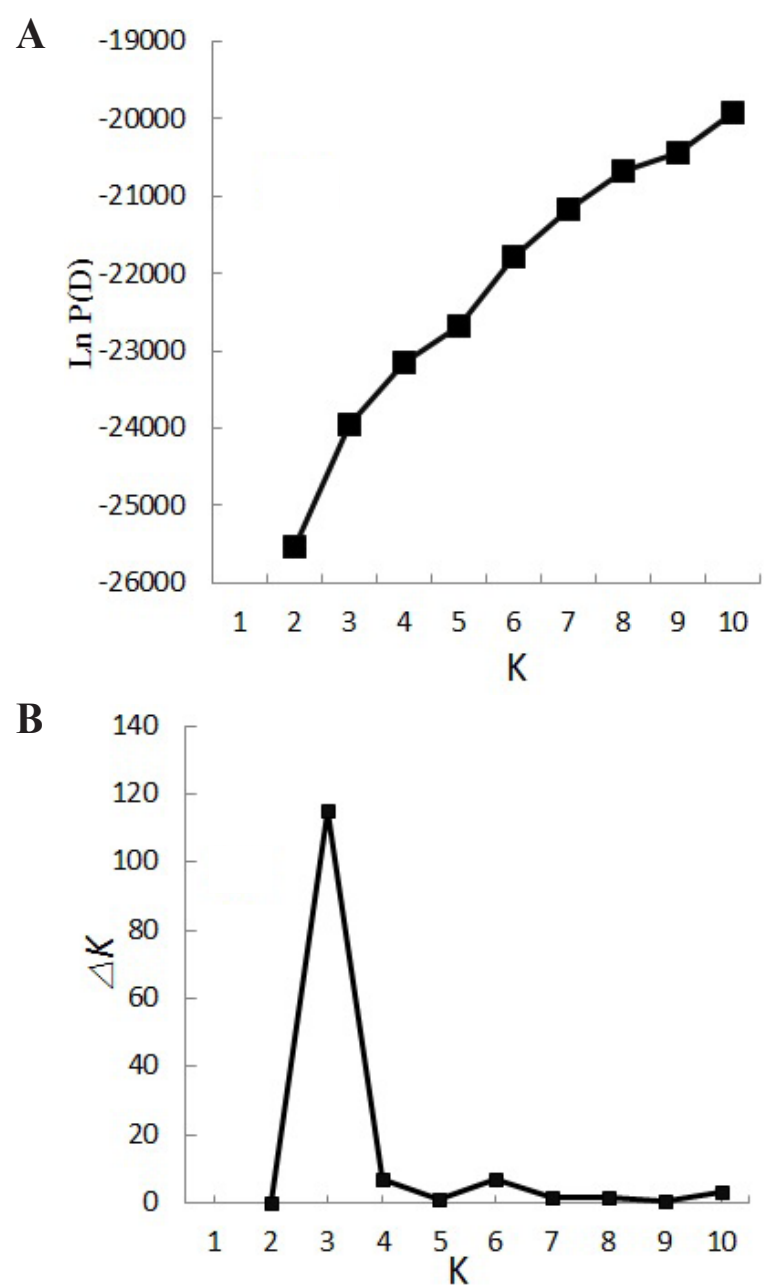

Figure 2. A. Log-likelihood of the data $(\mathrm{N}=394)$ as a function of $K$ (the number of groups used to stratify the sample). B. $\Delta K$, with its modal value detecting a true $K$ for the three groups $(K=3)$. For each $K$ value, five independent runs were considered; the data were averaged over the replicates.

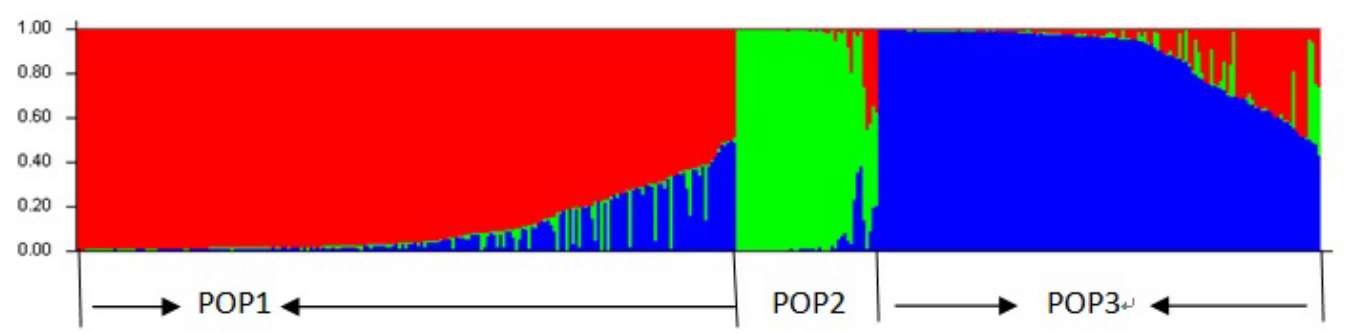

Figure 3. Model-based clustering for each of the 394 rice landrace accessions examined based on the 29 markers used to build the Q-matrix. The groups in each panel are represented by different colors. Each individual bar represents an accession. The y-axis displays the estimated ancestry for each individual in a particular gene pool. POP1-POP3 = populations 1,2 and 3. 
The distribution of molecular genetic variation among and within the 3 clusters of accessions was estimated by AMOVA, which revealed that $22.35 \%$ of the total variation was among clusters and $77.65 \%$ of the variation was within clusters (Table 4). Wright (1978) suggested qualitative guidelines for the interpretation of $F_{\mathrm{ST}}$. A range from 0 to 0.05 may be considered to indicate little genetic differentiation, whereas ranges from 0.05 to 0.15 and 0.15 to 0.25 and $F_{\mathrm{ST}}$ values $>0.25$ indicate moderate, great, and very great genetic differentiation, respectively. In this study, the overall $F_{\mathrm{ST}}$ value was 0.2235 , indicating moderate differentiation among the 3 groups (Table 5). A comparison of the GD, PIC, and MAF values in the 3 clusters is shown in Table 5. Among the 3 model-based populations, POP2 showed higher GD and PIC values than POP1 and POP3. In contrast, POP3 had lower GD and PIC values than POP1 and POP2, suggesting that POP3 is more homogeneous than the other POPs. Pairwise $F_{\mathrm{ST}}$ values were estimated to explain the genetic differentiation among the subpopulations (i.e., POP1, POP2, and POP3). The subpopulational pairwise $F_{\mathrm{ST}}$ values ranged from 0.4197 between POP1 and POP2 to 0.3575 between POP2 and POP3 (Table 5).

\begin{tabular}{|c|c|c|c|c|c|c|c|c|}
\hline \multirow[t]{2}{*}{ Cluster } & \multicolumn{5}{|c|}{ Diversity } & \multicolumn{3}{|c|}{$F_{\text {ST }}$} \\
\hline & $\mathrm{N}$ & $N_{\mathrm{A}}$ & MAF & GD & PIC & 1 & 2 & Overall \\
\hline$\overline{\mathrm{POP} 1}$ & 182 & 9.14 & 0.5400 & 0.5751 & 0.5380 & & & \\
\hline POP2 & 38 & 7.1 & 0.4855 & 0.6456 & 0.6115 & 0.4197 & & \\
\hline POP3 & 111 & 7.6 & 0.6024 & 0.5120 & 0.4806 & 0.1011 & 0.3575 & \\
\hline
\end{tabular}

\section{Phenotypic trait correlations and significance testing for the population genetic groups}

The results of our analysis based on 9 phenotypic and 5 physicochemical traits in 301 non-waxy landrace accessions are shown in Table 6 . A simple paired $t$-test and an association analysis were carried out to identify varieties and correlations exhibiting significant differences from the checked accessions. Traits having a positive significant correlation and some having a negative significant correlation among the phenotypic traits were identified. A strong association was present between eating quality and other physicochemical traits, including protein content $(\mathrm{r}=-0.262), \mathrm{K}^{+}$content $(\mathrm{r}=-0.655), \mathrm{Mg}^{2+}$ content $(\mathrm{r}=-0.680), 1000-\mathrm{GW}(\mathrm{r}=0.159)$, $\mathrm{AC}(\mathrm{r}=-0.134)$, and days to flowering $(\mathrm{r}=-0.123)$. DMRT was employed to determine whether there was any correlation between phenotypic traits and the 3 subpopulations of Korean rice landraces grouped by Structure. By analysis of variance, 10 of 14 phenotypic traits revealed significant differences $(\mathrm{P}<0.05)$. Multiple mean comparisons using DMRT revealed that the 1000-grain weight was significantly different among the 3 subpopulations. Phenotypic characteristics such as seed length, seed width, and 1000-grain weight were smaller in POP1 than in the other 2 POPs, whereas the awn number per seed and culm height were higher. Days to flowering and eating quality were significantly different only in POP2; the phenotypic traits showing a significant difference only in POP3 and POP1 were PC and culm height, respectively (Table 7). As a result, POP2 was discriminated from the other POPs in terms of the eating quality and days to flowering, and POP1 and POP 3 differed from each other in terms of culm height, PC, seed width, seed length, and awn number per seed (Table 7). 
Table 6. Correlation coefficients among several traits in the 301 non-waxy landrace accessions.

\begin{tabular}{|c|c|c|c|c|c|c|c|c|c|c|c|c|c|}
\hline Traits & $\mathrm{CH}$ & $\mathrm{SL}$ & SW & $\mathrm{NOA}$ & NOP & PL & SCC & DF & 1000-GW & $\mathrm{AC}$ & $\mathrm{PC}$ & $\mathrm{Mg}^{2+}$ & EQ \\
\hline $\mathrm{SL}$ & -0.025 & & & & & & & & & & & & \\
\hline SW & -0.041 & $0.146^{*}$ & & & & & & & & & & & \\
\hline $\mathrm{NOA}$ & $0.182^{* *}$ & $-0.147^{* *}$ & 0.005 & & & & & & & & & & \\
\hline NOP & -0.049 & 0.004 & $-0.143 * *$ & -0.051 & & & & & & & & & \\
\hline PL & $0.177^{* *}$ & 0.095 & -0.017 & 0.017 & -0.020 & & & & & & & & \\
\hline $\mathrm{SCC}$ & 0.016 & 0.096 & -0.010 & 0.027 & $0.126^{*}$ & -0.041 & & & & & & & \\
\hline $\mathrm{DF}$ & -0.052 & $0.204^{* *}$ & $0.233^{* *}$ & -0.076 & -0.069 & -0.017 & -0.100 & & & & & & \\
\hline $1000-\mathrm{GW}$ & -0.033 & $0.382 * *$ & $0.268^{* *}$ & -0.096 & $-0.136^{*}$ & 0.073 & 0.014 & 0.101 & & & & & \\
\hline $\mathrm{AC}$ & 0.079 & 0.020 & $-0.133^{*}$ & -0.064 & 0.116 & 0.022 & $0.232 * *$ & -0.116 & -0.047 & & & & \\
\hline $\mathrm{PC}$ & $0.136^{*}$ & 0.064 & -0.084 & 0.059 & 0.101 & -0.052 & $0.115^{*}$ & -0.075 & -0.059 & 0.031 & & & \\
\hline $\mathrm{Mg}^{2+}$ & 0.084 & -0.022 & 0.050 & 0.064 & 0.025 & 0.018 & $0.114^{*}$ & -0.021 & $-0.156^{* *}$ & -0.008 & $0.229^{* *}$ & & \\
\hline EQ & -0.062 & -0.098 & -0.016 & 0.017 & -0.064 & 0.011 & -0.061 & $-0.123^{*}$ & $0.159^{* *}$ & $-0.134 *$ & $-0.262 * *$ & $-0.680^{* *}$ & \\
\hline $\mathrm{K}^{+}$ & 0.030 & -0.056 & 0.032 & 0.009 & 0.022 & -0.020 & $0.110^{*}$ & 0.009 & $-0.171^{* *}$ & -0.086 & -0.011 & $0.812^{* *}$ & $-0.655^{* *}$ \\
\hline
\end{tabular}

$\mathrm{CH}=$ culm height $(\mathrm{mm}) ; \mathrm{SL}=$ seed length $(\mathrm{mm}) ; \mathrm{SW}=$ seed width $(\mathrm{mm}) ; \mathrm{NOA}=$ No. of awn per seed; NOP $=$ No. of panicle; $\mathrm{PL}=$ panicle length $(\mathrm{cm}) ; \mathrm{SCC}=$ seed coat color; $\mathrm{DF}=$ days to flowering (days); $1000-\mathrm{GW}=1000$-grain weight $(\mathrm{g}) ; \mathrm{AC}=$ amylose content; $\mathrm{PC}=$ protein content, $\mathrm{EQ}=$ eating quality. ${ }^{*}$ Correlation is significant at the 0.05 level (two-tailed). ${ }^{* *}$ Correlation is significant at the 0.01 level (two-tailed).

\begin{tabular}{|c|c|c|c|c|}
\hline Traits & POP1 & POP2 & POP3 & F value ${ }^{a}$ \\
\hline PC (\%) & $7.04^{\mathrm{a}}$ & $7.28^{\mathrm{a}}$ & $6.66^{\mathrm{b}}$ & $7.35^{* * *}$ \\
\hline $\mathrm{CH}(\mathrm{mm})$ & $98.23^{\mathrm{a}}$ & $88.56^{\mathrm{b}}$ & $88.95^{\mathrm{b}}$ & $15.66^{* * *}$ \\
\hline SL (mm) & $6.33^{\mathrm{b}}$ & $7.32^{\mathrm{a}}$ & $6.51^{\mathrm{b}}$ & $19.83 * * *$ \\
\hline $\mathrm{SW}(\mathrm{mm})$ & $3.31^{\mathrm{b}}$ & $3.39^{\mathrm{b}}$ & $3.68^{\mathrm{a}}$ & $5.46^{*}$ \\
\hline NOA & $2.95^{\mathrm{a}}$ & $2.34^{\mathrm{b}}$ & $2.02^{\mathrm{b}}$ & $13.61 * * *$ \\
\hline NOP & $9.45^{\mathrm{a}}$ & $8.47^{\mathrm{b}}$ & $9.67^{\mathrm{a}}$ & $3.66 *$ \\
\hline PL (cm) & $21.14^{\mathrm{a}}$ & $21.27^{\mathrm{a}}$ & $20.67^{\mathrm{a}}$ & 2.36 \\
\hline SCC & $1.14^{\mathrm{a}}$ & $1.09^{\mathrm{a}}$ & $1.03^{\mathrm{a}}$ & $5.70 *$ \\
\hline DF & $111.87^{\mathrm{b}}$ & $121.24^{\mathrm{a}}$ & $111.61^{b}$ & $9.31 * * *$ \\
\hline 1000-GW (g) & $23.17^{\mathrm{c}}$ & $26.41^{\mathrm{a}}$ & $24.26^{\mathrm{b}}$ & $12.52 * * *$ \\
\hline $\mathrm{AC}(\%)$ & $15.84^{\mathrm{a}}$ & $16.36^{\mathrm{a}}$ & $17.02^{\mathrm{a}}$ & 1.33 \\
\hline EQ & $69.40^{\mathrm{a}}$ & $64.97^{\mathrm{b}}$ & $69.91^{\mathrm{a}}$ & 2.28 \\
\hline $\mathrm{Mg}$ & $23.57^{\mathrm{ab}}$ & $24.98^{\mathrm{a}}$ & $22.09^{b}$ & $4.18 *$ \\
\hline K & $75.77^{\mathrm{a}}$ & $76.90^{\mathrm{a}}$ & $74.54^{\mathrm{a}}$ & 2.27 \\
\hline
\end{tabular}

$\mathrm{PC}=$ protein content $\mathrm{CH}=$ culm height $(\mathrm{mm}) ; \mathrm{SL}=$ seed length $(\mathrm{mm}) ; \mathrm{SW}=$ seed width $(\mathrm{mm}) ; \mathrm{NOA}=$ No. of awn per seed; $\mathrm{NOP}=$ No. of panicle; $\mathrm{PL}=$ panicle length $(\mathrm{cm}) ; \mathrm{SCC}=$ seed coat color; $\mathrm{DF}=$ days to flowering (days); $1000-\mathrm{GW}=1000$-grain weight $(\mathrm{g}) ; \mathrm{AC}=$ amylose content; $\mathrm{EQ}=$ eating quality, ${ }^{\mathrm{a}} \mathrm{F}$ value of ANOVA. $* * *$ Significant at $\mathrm{P}<0.001,{ }^{*} \mathrm{P}<0.05$. ${ }^{\mathrm{a}, \mathrm{b}, \mathrm{c}}$ Means along rows with different letters are significantly different $(\mathrm{P}<0.05)$.

\section{DISCUSSION}

In this study, 381 alleles were detected among 394 Korean rice landrace accessions using 29 SSR markers, with an average of 13.14 alleles per locus. This value is higher than that reported previously for landrace rice (Bajracharya et al., 2006; Pandey et al., 2011), indicating that Korean rice landraces possess strong GD, which may make them an important genetic resource for rice breeding programs and which could increase the utilization of rice landraces. All of the SSR markers were found to be polymorphic, and there was considerable genetic variation among the rice landrace accessions, with a mean $H_{\mathrm{E}}=0.5623, \mathrm{MAF}=0.5005, \mathrm{GD}=$ 0.6156 , and PIC $=0.5839$. Most of the SSR markers differed greatly in the number of alleles, ranging from 3 to 44 . Certain SSR markers producing similar numbers of alleles varied greatly in their $H_{\mathrm{E}}$, GD, and PIC values. For example, 3 alleles were detected at each of the markers 
RM6144, RM6165, and RM12676, but there was a significant difference in their $H_{\mathrm{E}}$, GD, and PIC values. A similar trend was reported previously in strawberry (Yoon et al., 2012) and Italian millet (Zhao et al., 2012a). Among the 29 SSR markers, RM206, RM48, RM214, RM232, and RM249 showed a comparatively high number of alleles and exhibited strong GD in the 394 Korea rice landrace accessions, as reported by Lee et al. (2006) and Zhao et al. (2009). The observed difference in GD and PIC may be attributed to the variation in allele frequency between the datasets for the 2 loci. A similar trend was reported previously in rice (Queller et al., 1993). The significantly high frequency of rare alleles (267 alleles, $70.1 \%$ ) among landrace accessions indicates that they make a greater contribution to the overall GD of the collection. The GD values for the 4 different AC groups are shown in Table 3. Our results show that the LAC varieties had the highest allele number (300), whereas the HAC varieties had the highest GD (0.7232) and PIC (0.6926). The GD and PIC values for the varieties decreased in the following order: HAC $>$ waxy $>$ LAC $>$ IAC. This preliminary finding suggests that the HAC varieties had the highest GD compared with other groups among Korea landrace rice. Our data will be useful in designing breeding programs and increasing the utilization of rice landraces.

Population genetics deals with variations in allele frequency between and within populations. The model-based method uses a Bayesian grouping approach to probabilistically assign individuals to populations based on their genotypic data and attempts to find a population structure in which the population is in Hardy-Weinberg equilibrium. The model does not assume a particular mutation process, and in most situations, the estimated log probability does not provide a correct estimation of the number of groups $(K)$ (Evanno et al., 2005). In our simulations, as the real $K$ was reached, $\mathrm{L}(K)$ at larger $K$ s plateaued or continued to increase slightly (Pritchard and Wen, 2003), and the variance between runs increased (Figure 2A). The distribution of $\mathrm{L}(K)$ did not show a clear mode for the true $K$, but $\Delta K$ did show a clear peak at $K=3$ (Evanno et al., 2005) (Figure 2B).

Our model-based structural analysis revealed the presence of 3 populations (POP1POP3) in the Korea rice landraces. When clustering based on the GD and structural analyses based on the model were compared, similar groupings of the accessions were discovered (Figure 3 and Figure S1). The degree of admixture, alpha $(\alpha=0.0739)$, was inferred from the data. When alpha is close to zero, most individuals are essentially from one population or another, whereas when alpha is $>1$, most individuals are admixed (Evanno et al., 2005; Ostrowski et al., 2006). The distribution of the 394 accessions that shared at least $70 \%$ ancestry with 1 of the 3 inferred groups is summarized in Table 5 . In addition to the groups identified by this analysis, $16 \%$ of the accessions showed evidence of mixed population ancestry. The mixture is likely the result of breeding, artificial selection, and domestication history, which have large effects on diversity. The independent population histories of the groups also shaped the gene pools (Garris et al., 2005). In this study, the $F_{\mathrm{ST}}$ values of the different groups ranged from 0.4197 between POP 1 and POP2 to 0.3575 between POP2 and POP 3 based on AMOVA, and the overall $F_{\mathrm{ST}}$ value was 0.2235 , indicating moderate differentiation within South Korean rice landraces (Table 5). A similar result was observed in Korea soybean landraces (Burnham et al., 2002).

Rice quality is a complex trait that includes many components such as milling, appearance, nutrition, and cooking and eating qualities. Among these qualitative properties, consumers pay most attention to fine appearance and high eating quality (Huang et al., 1998; Zhao et al., 2012b). AC is related to the appearance and texture of rice, and it affects cooking and eating quality (Bao et al., 2006; Lu and Park, 2012). Hence, regulating the AC in rice has been 
a major concern of rice breeders. The results of a simple paired $t$-test and correlation testing of 9 phenotypic traits and 5 physicochemical traits, including AC, are shown in Table 6 . There were highly significant correlations $(\mathrm{P}<0.05$ or 0.01$)$ among some traits, including $\mathrm{PC}, \mathrm{K}^{+}$, $\mathrm{Mg}^{2+}$, and AC. These results agree with those of Zeng et al. (2005) and Jiang et al. (2007). By DMRT using the same 9 phenotypic and 5 physicochemical traits, significant differences were observed among the 3 groups in 10 qualitative and quantitative traits.

Landraces of rice are thought to be an intermediate stage in the domestication process from the wild ancestor to cultivated rice. Thus, they represent a unique and critical source of genetically variable traits that can serve as a resource for future rice improvement. Assessments of GD are an essential component in germplasm characterization and conservation. This preliminary study could be the first step toward more efficient conservation and utilization of rice landraces to broaden the genetic bases of commercially grown varieties.

\section{ACKNOWLEDGMENTS}

Research supported by a grant from the BioGreen "21” Program (\#PJ009039), Rural Development Administration, Republic of Korea.

\section{Supplementary material}

\section{REFERENCES}

Association of Official Agricultural Chemists (AOAC) (2005). Official Methods of Analysis of AOAC International. 18th edn. AOAC International Gaithersburg.

Bajracharya J, Steele KA, Jarvis DI and Sthapit BR (2006). Rice landrace diversity in Nepal: Variability of agromorphological traits and SSR markers in landraces from a high-altitude site. Field Crops Res. 95: 327-335.

Bao JS, Corke H and Sun M (2006). Analysis of genetic diversity and relationships in waxy rice (Oryza sativa L.) using AFLP and ISSR markers. Genet. Resour. Crop. Evol. 53: 323-330.

Burnham KD, Francis DM, Dorrance AE and Fioritto RJ (2002). Genetic diversity patterns among phytophthora resistant soybean plant introductions based on SSR markers. Crop Sci. 42: 338-343.

Evanno G, Regnaut S and Goudet J (2005). Detecting the number of clusters of individuals using the software STRUCTURE: a simulation study. Mol. Ecol. 14: 2611-2620.

Falush D, Stephens M and Pritchard JK (2003). Inference of population structure using multilocus genotype data: linked loci and correlated allele frequencies. Genetics 164: 1567-1587.

Garris AJ, Tai TH, Coburn J, Kresovich S, et al. (2005). Genetic structure and diversity in Oryza sativa L. Genetics 169: 1631-1638.

Giarrocco LE, Marassi MA and Salerno GL (2007). Assessment of the genetic diversity in Argentine rice varieties with SSR markers. Crop Sci. 47: 853-858.

Gupta PK and Varshney RK (2000). The development and use of microsatellite markers for genetic analysis and plant breeding with emphasis on bread wheat. Euphytica 113: 163-185.

Hammer K (2005). Korea's importance in the East Asiatic gene center. Genet. Res. Crop Evol. 52: 115-116.

Huang FS, Sun ZX, Hu PS and Tang SQ (1998). Present situations and prospects for the research on rice grain quality forming. Chin. J. Rice Sci. 12: 172-176.

Jeong OY, Song MT, Hong JH and Lee KS (1999). Comparison of PCR-based DNA fingerprinting methods using random, microsatellite, and STS primers for the classification of Korean rice varieties. Korean J. Genet. 21: 157-169.

Jiang SL, Wu JG, Feng Y, Yang XE, et al. (2007). Correlation analysis of mineral element contents and quality traits in milled rice (Oryza stavia L.). J. Agric. Food Chem. 55: 9608-9613.

Juliano BO (1971). A simplified assay for milled-rice amylose. Cereal Sci. Today 16: 334-340.

Juliano BO (1998). Varietal impact on rice quality. Cereal Foods World 43: 207.

Lee JK, Chung JW, Park YJ and Ma KH (2006). Assessment of genetic diversity of Korean landrace rice accessions 
(Oryza sativa L.) by microsatellite analysis. Korean J. Breed. 38: 75-82.

Li G and Park YJ (2012). SCAR markers for discriminating species of two genera of medicinal plants, Liriope and Ophiopogon. Genet. Mol. Res. 11: 2987-2996.

Liu K and Muse SV (2005). PowerMarker: an integrated analysis environment for genetic marker analysis. Bioinformatics 21: $2128-2129$.

Lu FH and Park YJ (2012). Sequence variations in OsAGPase significantly associated with amylose content and viscosity properties in rice (Oryza sativa L.). Genet. Res. 94: 179-189.

McCouch SR, Teytelman L, Xu Y, Lobos KB, et al. (2002). Development and mapping of 2240 new SSR markers for rice (Oryza sativa L.). DNA Res. 9: 199-207.

McNally KL, Childs KL, Bohnert R, Davidson RM, et al. (2009). Genomewide SNP variation reveals relationships among landraces and modern varieties of rice. Proc. Natl. Acad. Sci. U. S. A. 106: 12273-12278.

Moe KT and Park YJ (2012). Analysis of population structure revealed apparent genetic disturbance in Korea Cymbidium collection. Sci. Hortic. 134: 157-162.

Ostrowski MF, David J, Santoni S, McKhann H, et al. (2006). Evidence for a large-scale population structure among accessions of Arabidopsis thaliana: possible causes and consequences for the distribution of linkage disequilibrium. Mol. Ecol. 15: 1507-1517.

Pandey A, Bisht IS, Bhat KV and Mehta PS (2011). Role of informal seed system in promoting landrace diversity and their on-farm conservation: a case study of rice in Indian Himalayas. Genet. Resour. Crop Evol. 58: 1213-1224.

Perez CM and Juliano BO (1978). Modification of the simplified amylose test for milled rice. Starch 30: 424-426.

Pritchard JK and Wen W (2003). Documentation for STRUCTURE Software: Version 2.3. Department of Statistics University of Oxford, Oxford.

Pritchard JK, Stephens M and Donnelly P (2000). Inference of population structure using multilocus genotype data. Genetics 155: 945-959.

Queller DC, Strassmann JE and Hughes CR (1993). Microsatellites and kinship. Trends Ecol. Evol. 8: 285-288.

Rabbani MA, Iwabuchi A, Murakami Y and Suzuki T (1998). Genetic diversity in mustard (Brassica juncea L.) germplasm from Pakistan as determined by RAPDs. Euphytica 103: 235-242.

Satheeshkumar P and Saravanan K (2012). Genetic divergence analysis for grain yield and quality traits in rice (Oryza sativa L.). Plant Arch. 12: 639-644.

Schuelke M (2000). An economic method for the fluorescent labeling of PCR fragments. Nat. Biotechnol. 18: 233-234.

Song MT, Lee JH, Cho YS and Jeon YH (2002). Narrow genetic background of Korean rice germplasm as revealed by DNA fingerprinting with SSR markers and their pedigree information. Korean J. Genet. 24: 397-403.

Sun CQ, Wang XK, Li ZC and Yoshimura A (2001). Comparison of the genetic diversity of common wild rice (Oryza rufipogon Griff.) and cultivated rice (O. sativa L.) using RFLP markers. Theor. Appl. Genet. 102: 157-162.

Tamura K, Dudley J, Nei M and Kumar S (2007). MEGA4: Molecular Evolutionary Genetics Analysis (MEGA) software version 4.0. Mol. Biol. Evol. 24: 1596-1599.

Wright S (1978). Evolution and the Genetics of Populations. Variability Within and Among Natural Populations. Vol. 4. University of Chicago Press, Chicago.

Yeh F, Yang R and Boyle T (1999). POPGENE. Version 1.31. Microsoft Window-Based Freeware for Population Genetic Analysis, University of Alberta. Edmonton.

Yoon MY, Moe KT, Kim DY and Rho RI (2012). Genetic diversity and population structure analysis of strawberry (Fragaria $\mathrm{x}$ ananassa Duch.) using SSR markers. Electron. J. Biotechnol. 15: 71-85.

Zeng YW, Shen SQ, Wang LX and Liu JF (2005). Correlation of plant morphological and grain quality traits with mineral element contents in Yunnan rice. Rice Sci. 12: 101-106.

Zhao WG, Chung J, Ma KH and Kim T (2009). Analysis of genetic diversity and population structure of rice varieties from Korea, China and Japan using SSR markers. Genes Genomics 31: 283-292.

Zhao WG, Lee GA, Kwon SW and Ma KH (2012a). Development and use of novel SSR markers for molecular genetic diversity in Italian millet (Setaria italica L.). Genes Genomics 34: 51-57.

Zhao WG, Chung J, Kwon SW and Lee J (2012b). Association analysis of physicochemical traits on eating quality in rice (Oryza sativa L.). Euphytica 1: 13. 